\title{
Book Review: Kelly A. McGuire's Hotel Pricing in a Social World
}

\author{
Belachew Kassahun \\ Lecturer, Department of Tourism and Hotel Management, College of Business and Economics, Bahir Dar \\ University, Ethiopia
}

TITLE OF BOOK: Hotel Pricing in a Social World

AUTHOR: Kelly A. McGuire

Nairobi: Published by John Wiley \& Sons, Inc., 2016, 329 pages

COVER: Paperback

ISBN: 9781119129967

DOI: $10.7176 / \mathrm{JMCR} / 71-04$

Publication date:September $30^{\text {th }} 2020$

The hotel industry today is "constantly changing" Worldwide. Globalization and the industry's wide focus on sustainability are just some of the forces and resulting in widespread change. The result is an industry that requires to leader in service sector as well as in hospitality. To this end, the First Edition of Hotel Pricing in a Social World features both practical perspectives and discussions of new trends in a variety of sectors. The book aims to provide extensive knowledge, skill and ethics to practitioners, educators and students with the most up-to-date content with the hope that the next generation of hospitality leaders will be fully prepared to great the challenges of this dynamic industry.

The publication of Hotel Pricing in a Social World is most timely, it addresses the key aspects of revenue management, and paves the way to hotelier a new level knowledge in today's competitive marketplace since revenue management is an incredibly hot topic for well-conceived revenue strategies and tactics can grow a hotel's market share and profits significantly. With an emphasis on excellence and best practice, Kelly guides the reader through the book by focusing on key messages presented in an uncomplicated and readily absorbed style. Using the themes of New Analytics for a New Environment: The Evolution of Hotel Revenue Management Analytics, Technology, and Data, The Expanding Role of Revenue Management, The Future of Revenue Management: Pricing as a Business Strategy, the author identifies those aspects of the hotelier's role where changes in changes in marketplace, technology, and consumers, and the impact that they will have on your business.

Hotel Pricing in a Social World is the pioneer hotel management book as I have read that is actually practical, realistic, and informative and navigates new forces which allows practitioners to develop the knowledge and skills required and do exactly what is on the ground to run a great hotel. This, therefore, is vital, for all of the challenges facing the hotel industry; the availability of competent and dedicated people remains by far the greatest.

In Addition, it is fascinating how Kelly simply translated industry thought of his long years' experience with challenges old conventions of revenue management and pricing. He also breaks down the theoretical background of revenue management theories into practical advice in to a hotel and travel industries. It is not only the easy description of some complicated revenue management but also the implementation in clear examples and very useful forms that makes the book into a kind of bible for integrating consumer psychology into the discipline of revenue management and pricing, through the application of big data and advanced analytics for every hotelier that wants to be successful. It is this easy to understand language and the translation into practical tips that makes the book so useful in daily life, even for the very experienced hotelier.

Hotel Pricing in a Social World is a wonderful exploration of pricing strategy with a strong customer focus to achieve excellence in the hotel industry. Excellence principles tied together with author's rich personal experiences make it an interesting, powerful and an easy to read format. Pricing strategies is practical, with a howto focus, and includes toolkits which can be used by practitioners and trainers in the field as it evolve with the changing mind set of the customers. It is a great text for those interested in achieving excellence in hospitality and related firms management and for those who want to experience what revenue management in hotels is really like.

Hotel Pricing in a Social World is a must, timely and relevant. In this book Kelly puts customers at the center of success for how revenue management systems today should take advantage of innovations in analytics and data visualization to drive more profitable business decisions. It will help industry leaders, hotel developers, hotel general managers, asset managers and brand owners will all benefit by reading the book and pondering its recommendations as relates to their particular area of interest and involvement. It will provide opportunities for revenue management to the tools that managers use to help them achieve their goals. Using theories, examples, and case histories, these nine chapters portray the management function as an active force for solving problems those hospitality organizations face and encourage to step out of the box, embrace innovations, and develop a holistic understanding of consumer behavior. It is a book that will give practitioners the road map to transform the revenue management capabilities and build a sustainable long-term competitive advantage for hospitality 
organizations.

This book has been possible published with the contribution of comprised of a team of domain experts in hospitality, gaming, travel, transportation, communications, media, entertainment, and the midmarket. The author particularly for this book used questions, comments, and discussion points from hundreds of conversations and make it through his attractive analysis of what has been on the ground in the hotel industry. His leadership at SAS's Services practice helps brings the issue of pricing as an increasing number of hoteliers recognize the need for excellence along pricing. As levels of quality increase across the industry, hoteliers which continuously improve their offering will not soon be overtaken and eventually enlarge their market share.

Kelly A. McGuire's industry professional experience and education he has had assisted in the preparation of the text. In his book, he emphasizes the importance of striving for excellence as the major driver of business growth and profitability. He helps new and experienced hoteliers to more clearly understand what excellence revenue management in this competitive edge means in practice, why it is of essential interest today to bring it alive in business so that you truly out-perform competitors. The book has a lot of contribution for many people who are working in academia, and I am one of those beneficiaries using the academic work of author Kelly. Currently, I am using this book as reference book for course I am teaching for undergraduate students specifically as Food and Beverage Control, introduction to hotel operation as well as Front Office Management. The editing and production of this book is great with its shepherding a convenient typescript, smooth illustrations, and a lot of pictures author has done into the book so with the utmost professionalism. From my observation, I have truly not found any weaknesses and limitations sides from the book. I suggest all of hoteliers, academicians, undergraduate and postgraduate students of the field to use this book to get intense knowledge for professional and career development. I feel very fortunate to have learned from his many years of experience and insights. Generally, the book is qualified to academics and professionals for use in their courses during the academic work and professional work. Finally, this book should be on the desk of every practitioners and academicians searching for excellence in the hotel industry and to become a leader in the industry as to feel much more confident making decisions after reading this book. To help us as we get knowledge, review, develop our hotel business plan, Kelly has included a section with practical steps towards excellence. 